\title{
From potential to realisation: an episode in the origin of language
}

\author{
Bernard Comrie
}

\section{Introduction}

This is a speculative paper, dealing with one facet of the origin of human language. ' While I make no attempt to hide its speculative nature, I believe that we do now have available to us empirical material that bears on the question I address and that can serve at least to narrow down the range of possible answers. But first, I wish to introduce Dumbo the flying elephant, as this will lead directly into the main question to be posed.

It might not be immediately clear what Dumbo the flying elephant has to do with the origin of language. Those familiar with the story of Dumbo will recall that he was able to fly, but that for the earlier part of his life he was unaware that he had this ability and did not in fact utilise it. When placed in a situation where his life depended on being able to fly, he made the attempt and flew. This is, of course, fiction, but there is an analogy that carries over to one aspect of the origin of language. Let us suppose that a particular creature has the genetic ability to carry out a certain behaviour. What factors in the environment are necessary to bring the creature in question actually to manifest that behaviour?

More specifically, I wish to address this question with respect to language. I will assume a point in time at which human beings had the necessary genetic ability to create language. I will remain neutral as to how detailed that genetic ability is, that is, as to the division of labor between nature and nurture in the development of any particular language in its speaker(s), though I will assume, probably uncontroversially, that some of the ability to speak a particular language is given genetically and that some is determined by the linguistic environment. But I am not here concerned with how human beings came to have whatever genetic endowment they have in order to make language acquisition possible.

Given a human being with such genetically determined linguistic ability, what circumstances are necessary for this ability to be realized? There are many possible answers, and there remains much room for speculation about the correct answer or range of answers. Nonetheless, it seems that empirical 


\section{Bernard Comrie}

work, especially in recent years, may enable us at least to narrow down the range of possible answers.

My original interest in this question arose somewhat indirectly, namely from an interest in whether all human languages share a common origin. A clear way of disproving the monogenetic thesis would be to find one that has a demonstrably different origin. This then feeds into the question of the circumstances under which such a language could arise. In the present article, I concentrate on this latter question, although the answer to this question will, of course, have implications for the probability that human languages have a common origin. For the lower the likelihood of a new language arising ex nihilo in a human, the greater the likelihood that all languages have a single origin, since the single-origin hypothesis would require only a single occurrence of what I would like to call the Dumbo Factor, that is, the recognition on the part of a member of the species that communication by language is possible and the practical realization of this means of communication. However, nothing in this paper will come even close to answering this question.

\section{The range of scenarios}

At one extreme, we may consider ordinary child language acquisition. The child is a member of a particular speech community and grows up to speak the language of that community. While the child goes through acquisitional stages that are at times very different from that of the adult community, there is nonetheless remarkable convergence on the adult language goal. In particular, under normal conditions, children do not (with the possible exception of twin languages; see section 4.2) create their own languages as a long-term solution to the problem of their communication needs. (I deal briefly in section 4.1 with constructed languages, such as Esperanto.) An important additional factor is that successful language acquisition normally requires that the acquisition take place within a quite narrow developmental window.

Indeed, one can go even further. Under these normal circumstances, it seems that normal children cannot help but acquire the language of their speech community; in other words, whatever role instruction and correction may play in fine-tuning the child's linguistic knowledge, the basic linguistic knowledge is independent of such explicit guidance. One might therefore wonder whether a child would not come up with a language - not of course 
that of any existing speech community - even in the absence of input. This was, for instance, the view of Johann Gottfried Herder, whose 1772 publication proposed that simply by virtue of being human, a human being will, even in isolation, come up with human language as a communication system. (It presumably also underlies experiments like that attributed to King Psammetichus of Egypt, who, as related by Herodotus, caused two children to be reared in isolation to see which language they would end up speaking; this presupposes that they would end up speaking a human language and goes further in also presupposing that there is some particular language - according to Herodotus, their first word was the Phrygian for 'bread' - that they would speak as a default.)

One can add a related observation. Whatever the origin of human language, we know of no human community that lacks human language, even though there are human communities that lack most of the other abilities that distinguish humans from nonhumans. This applies equally to what is probably the most isolated known human group, namely the Tasmanians, who were isolated from the rest of mankind for over 10,000 years: from the flooding of the Bass Strait, which cut Tasmania off from the mainland of Australia, until the arrival of European explorers and in particular settlers at the beginning of the nineteenth century, at which time the Tasmanians numbered about 3,000 to 5,000. Although little is known of the languages of the Tasmanians, as a result of the genocide visited upon them by early settlers, it is clear that they did have language. We thus know of no human community that has abandoned language as its basic means of communication. ${ }^{2}$

The kind of test cases that are particularly relevant to our question are thus those where children are exposed to restricted input, where "restricted input" can vary in different degrees from the kind of input to which normal children are exposed under normal circumstances.

In what follows, I will be interested in the possible acquisition of a communication system that is comparable in complexity to what is found among normal speech communities. Bickerton (1990) introduces a concept of "protolanguage", exemplified for instance by pidgins, and perhaps by the communication systems acquired by apes in captivity, which can serve as rudimentary communication systems but which lack the complexity of normal human languages, in particular complex syntax. I am concerned specifically with the acquisition of language, not of protolanguage. 
106 Bernard Comrie

\section{Restricted input}

In this section, I will examine three sets of circumstances under which it is the case, or might be the case, that children are exposed to restricted input, and examine the consequences for language acquisition.

\subsection{Feral children and related cases}

In the most literal sense, a feral child would be one who has been deprived of all human contact. Whether such a child would ever survive is doubtful, so actual cases come close to the literal sense rather than exactly matching it. Unfortunately, most supposed cases of feral children are woefully lacking in adequate documentation, certainly in the kind of documentation necessary for a scientific evaluation. But there is one reasonably well-documented case, that of the twins Kamala and Amala, described by the Reverend J.A.L. Singh in his diaries from 1920 to 1929 and published in Singh and Zingg (1942: 1-118).

The two girls Kamala and Amala were found, apparently uncared for and certainly unable to speak any human language, in 1920 and taken into the care of the orphanage attached to Singh's mission station. Kamala's age was then estimated at eight years, i.e., well into the period at which a normal child under normal circumstances would have been acquiring language, and Amala's at one-and-a-half (Singh and Zingg 1942: 11), namely, a time when language acquisition might well not yet have manifested itself, even in a normal child under normal circumstances. The fact that two children are involved is potentially interesting, since they do constitute a potential minicommunity, in other words, one in which whatever social circumstances are necessary for language development might have been met. However, given Amala's probably young age, and the fact that she died the following year, it is doubtful whether this potential interest could actually have been expected to be realized. Kamala remained with Singh's mission until she died in 1929.

Singh's diary is not primarily concerned with her linguistic development. As a clergyman he was much more interested in her moral development and to some extent in her physical behaviour, for instance the (partial) shift from quadrupedal to bipedal gait. Nonetheless, the earlier part of the diary does contain a certain amount of linguistic information. As the diary progresses, unfortunately, the linguistic information becomes increasingly 
sparse and general, so that I do not feel that I have anything like a clear grasp of her linguistic abilities towards the time of her death. But from what Singh's account does say about her language, it seems that she acquired a pidgin-like competence in Bengali, the language of Singh's mission, without ever progressing beyond this. Moreover, there is no clear discussion of her general mental abilities, so the possibility cannot be excluded that language development might have been impaired by more general cognitive deficiencies.

If Kamala did have a normal general mental level yet failed to progress beyond the protolanguage stage, then in one case where it is reasonably clear that a child had no or minimal linguistic input up to the age of about eight, that child did not subsequently succeed in acquiring a knowledge of language comparable to that of a normal child under normal circumstances. If the estimate of Kamala's age at about eight was correct, then this would suggest a rather narrow time window within which language acquisition must at least start. (However, in response to a question from a medical doctor, Singh adds in a footnote to the published version of the diary [Singh and Zingg 1942: 11] that the age estimates were based on guesswork, in which case poor nutrition or other factors could have led to an abnormally smaller body. The only medical evidence concerns tooth eruption, but even here the footnote says that no systematic record was kept.)

A related case is that of Genie, described with scientific accuracy in Curtiss (1977). Genie (this is a pseudonym) was discovered at age 13 after having been kept imprisoned and isolated from exposure to language from about age one-and-a-half. At the time of her discovery, she was incapable of speech, thus providing even more direct evidence that absence of all input will probably lead to the absence of language development. However, in Genie's case one cannot exclude the possibility that general maltreatment might also have been a factor. But on examination, her general mental abilities turned out to be within the range of normal children.

Genie did subsequently acquire the ability to use a form of English as a means of linguistic communication, but her abilities in English were clearly not those of one who has acquired English under normal conditions. While Curtiss (1977) provides extensive illustration of Genie's speech, there remain possibilities for different interpretations of just how much progress Genie made in acquiring English. Curtiss emphasises Genie's achievements, noting utterances that seem to evince quite complex syntax. Bickerton (1990: 115-118), however, interprets Genie's failures as indications that she has acquired protolanguage rather than language; for instance, he claims 


\section{Bernard Comrie}

that apparent instances of complex sentences (involving subordination) may rather be interpreted as fixed formulae (1990: 116-117).

Although certain questions remain, the material discussed in this subsection suggests that in the absence of any input during the crucial time window, not only will a child not develop a human language spontaneously, but also the absence of language development during this critical period will mean that the child will not subsequently be able to advance beyond the stage of protolanguage.

\subsection{Creoles}

The question of the origin of creoles is perhaps one of the most controversial questions in current linguistics, and it is not my aim here to adjudicate among competing positions, but rather to assess their relevance for the general question posed in this article. Creoles are of particular interest because, at least to a considerable extent, they involve the creation of a new language, one that is substantially distinct from any of the languages that enter into its creation.

One part of creole genesis seems to be reasonably clear, namely that the lexicon of a creole comes from one or more of the languages of the communities that are involved in the building of the community in which the creole comes to be spoken, hereafter referred to as the contributing languages. In the most typical (for social and historical reasons) instances of creole genesis, the lexicon comes primarily from the superstrate language, with contributions ranging from highly significant to quite marginal from the substrate language(s). Although making up a lexicon might seem a priori to be the easiest part of creating a new language, in practice it seems to be the option that is least often, if ever, resorted to. By lexicon, incidentally, I mean essentially the forms of lexical items and their core meanings. The precise range of a lexical item may be influenced by the semantics of a language other than the one that contributes the form, but the core meaning will coincide, as in the case of Ndyuka futu 'foot, leg', where the semantic range of the English-origin form is broader than that of English foot (Huttar and Huttar 1994: 609-610).

However, given the nature of a plantation society, for the majority of members of the community access to the superstrate language is limited, particularly the kind of access that would lead to adoption of the grammar of the superstrate language. The controversy surrounds precisely the origin 
of creole grammar. Some researchers claim that the grammar comes largely from the contributing languages, and Lefebvre (1998) argues at length that the grammar of Haitian Creole comes primarily from the substrate language Fongbe. If it is the case that the grammar of creoles comes largely from the contributing languages, then creole languages essentially cease to be of interest for our present enterprise, since neither in lexicon nor grammar do they illustrate creation anew of a language. (There is, of course, no reason why a group of languages should necessarily be of interest to the present enterprise. Indeed, the vast majority of the world's languages, the product of regular transmission from generation to generation, clearly are not. The comments in this paragraph are thus quite irrelevant to the evaluation of Lefebvre's relexification hypothesis of creole genesis.)

An alternative hypothesis suggests that the grammar of a creole does not come from any of the contributing languages, but is instead created by children whose input is the fluctuating grammar of adults; these adults are native speakers of a range of languages, who have developed a common lexicon, largely on the basis of the superstrate language, but who lack any consistent grammar and are in fact operating with what we have seen Bickerton call a protolanguage. Given that there is no systematic grammatical input, the children have to make up their own grammar, that is, to create this part of the language anew. On the basis of similarities among creole languages with different contributing languages, a point returned to by McWhorter (1998) and Bickerton $(1984,1999)$ argues not only that children create grammar anew, but that there is a specific path laid down genetically for them to follow. In this bioprogramme hypothesis there is a particular set of unmarked values for the major parameters along which languages can vary, and in the absence of positive evidence to the contrary children opt for the unmarked values. For my present purposes, it is actually irrelevant whether this specific bioprogramme hypothesis is correct, since the mere fact of creation of grammar anew, however it is done, would satisfy the requirement of part of a language being created anew and not on the basis of input. Moreover, there are accounts other than the bioprogramme hypothesis that are candidates in accounting for typological similarities across creoles, for instance the more functional approach of Seuren and Wekker (1986).

Given the controversy within creole studies - see Muysken and Smith (1990) for further contributions - we cannot use creoles as a clear case of creation of a language or part of a language ex nihilo. At best we can say that if it is true that creole grammar has been created ex nihilo, then creoles are 


\section{Bernard Comrie}

directly relevant and illustrate the rapid creation of a language on the basis of a given lexicon only. But this is a big if.

\subsection{Deaf sign languages}

Perhaps because of the "muddy" - to use a term suggested to me by Pieter Muysken - nature of the creole data, attention has shifted more recently to another kind of language where there may be more cogent evidence for creation anew, namely deaf sign languages. By "deaf sign language" I mean specifically a signed communication system that is the basic medium of communication of a community (which will typically consist largely of deaf members) and that is of a complexity comparable to that of spoken languages that are the basic medium of communication in hearing communities. The recent expansion of sign language studies has shown that such languages exist and, moreover, that they are not derivative of the spoken languages of the same or neighbouring communities, neither in their lexicon nor in their grammar. For an early but cogent demonstration of the extent to which American Sign Language (ASL) differs grammatically from English, reference may be made to Klima and Bellugi (1979).

Although ASL is by far the best studied sign language, one disadvantage for our purposes is that the language was already in place when it began to be studied scientifically, so that we have no direct evidence of the early stages of its development. One point, however, that can be resolved concerning the lexicon (the actual shapes of the signs) is that at least many of them were initially iconic but rapidly lost their iconicity (Klima and Bellugi 1979: 67-83; as noted on page 67, this chapter was written by Nancy Frishberg). For instance, the sign for 'sweetheart' was originally made with the hands on the heart, iconic of the folk identification of the heart as seat of emotions connected with affection, but is now made in the centre of the chest (Klima and Bellugi 1979: 74-75). This is interesting in that, for the first time, we see a possible ultimate origin for the lexicon, although the extent to which this can be extended to the lexicons of spoken languages remains unclear to me. But it is equally interesting that even in cases of transparent iconic origin, there is a rapid diachronic shift to arbitrary signs so characteristic of human language. ${ }^{3}$

Fortunately, another sign language has been studied scientifically from within at most a few years of its creation, namely Nicaraguan Sign Language (NSL) (Senghas 1995, Kegl et al. 1999; see also Stokoe 1995: 
334). NSL arose around 1980, when for the first time deaf children in Nicaragua were brought together in schools for the deaf. Scientific investigation began in 1986. NSL did have a precursor in the Lenguaje de Signos Nicaragüense,${ }^{4}$ a protolanguage "home sign" in Bickerton's sense, that lacked many of the grammatical prerequisites of a fully fledged language. Senghas argues that in the brief period separating the creation of NSL from the time of her investigation, the grammar of NSL had expanded to include just these grammatical prerequisites. Thus, NSL in particular, and perhaps sign languages more generally, seem to provide evidence of the creation of grammar anew.

One thing that is interesting from the viewpoint of the bioprogramme hypothesis mentioned in relation to creoles in section 3.2 is that deaf sign languages seem to share typological traits that distinguish them from creole languages. For instance, David Perlmutter informs me that all known deaf sign languages have the phenomenon of "verb agreement" (Klima and Bellugi 1979: 276-279, where it is referred to as "referential indexing"), whereby the sign for a verb involves either location at, motion from, or motion to the location(s) that have been assigned to its arguments. For instance, the sign for "give" will move from the location assigned to the giver to the location assigned to the recipient. There is nothing like this in creoles, which are noted rather for their extreme paucity of inflectional morphology (McWhorter 1998: 792-793); nor indeed in spoken language generally, where there seems to be no analogue to location in deaf sign languages. This opens up even further possibilities for investigation of where the constituent features of newly emergent grammars come from. But the basic observation remains that, certainly in the case of deaf sign languages and perhaps in the case of creoles, grammar is created anew.

A further point that emerges from the work on NSL is the apparent need for a sufficiently large community of signers for a deaf sign language to take off, and the need for a continuous stream of new cohorts; in the case of NSL, a second cohort of children entering the system, some ten years after the first, modified the efforts of the first cohort in the direction of more stable encoding of certain semantic values. In the absence of such continuous input, as documented by Ragir (2000), deaf communities do not develop beyond the protolanguage stage. Finally in this section, we should cite one well documented case (Schaller 1991) of a deaf man (known in the literature as Ildefonso) who grew up away from contact with any deaf sign language or, apparently, even home sign. As an adult, though socialised in other respects, he was not only without a language but even had difficulty grasping 


\section{Bernard Comrie}

the concept of arbitrary signs when confronted with them. Thus, whatever the cognitive prerequisites for language acquisition and language creation, there are clearly also social constraints.

\section{Supplementary creation}

In this section I will examine cases in which there is already a community language, or at least access to a community language, but nonetheless individuals create a distinct language.

\subsection{Artificial languages}

Artificial languages, such as Esperanto and Klingon, seem to bear primarily on social aspects of the question of language origin and language continuity. It is clear that there are artificial languages that have been deliberately created, in most cases probably closely following the lexicons and grammars of European languages, as with Esperanto. Other cases depart far from these norms, like Klingon, created for the Klingons in the Star Trek series and films and the subject of a substantial cult following. There are instances of adults learning such languages with high levels of success, most notably in the case of Esperanto, and, again especially in the case of Esperanto, of children being brought up with such languages as their native languages.

Thus, it is clearly possible for humans who already speak one or more natural languages to create new languages in this way and for them to become native languages. And such languages might be clearly unrelated genetically to existing languages, even if the most successful cases of artificial languages have been quite close lexically and typologically to the languages spoken by their creators. In the overall history of human language, however, artificial languages have surely played a minor role, if indeed they have played any lasting role at all. Humans acquire a language in childhood within their speech community; social circumstances might lead them subsequently to learn another language, and perhaps even to rear their children bilingually. But all of this involves the transmission of already existing languages. People have no need to create artificial languages, and it is doubtful if many in premodern times have even sought to do so.

So artificial languages, though clearly possible, are not an integral part of the overall scenario that is being constructed in this article. 


\subsection{Twin languages}

There is, however, another set of circumstances under which a new language can arise, apparently unnecessarily. It has been noted that twins often develop a communication system between themselves that is not comprehensible to others, particularly to other members of their speech community, indeed of their family. The fullest study of twin languages (also called autonomous languages) is Bakker (1987), on which I rely heavily here.

Although at first the lexicon of a twin language appears to be idiosyncratic, closer investigation has in each documented case revealed that the lexicon is heavily parasitic on the language(s) spoken in the twins' community. The forms of lexical items often undergo substantial phonetic transformation, usually in ways typical of child phonology more generally, but with the difference that these forms then become fossilised in use between the twins. Thus, even though the resulting forms are usually incomprehensible to outsiders, they are clearly derived from the language(s) of the twins' input, so that there is no question of creating a lexicon ex nihilo.

Bakker's conclusion on examining the grammars of twin languages is that the grammars are not necessarily similarly derivative of the grammars of the input language(s). Indeed, as the subtitle of Bakker (1987) suggests, the author entertains the possibility, on the basis of grammatical similarities among twin languages, that they may represent a default setting of parameters along the lines of Bickerton's bioprogramme (see section 3.2). In any event, there is much more innovation in the grammar than in the lexicon of twin languages. And in the case of twin languages, of course, there are no other possible sources of the grammar as with the substrate languages of creoles.

Thus, the twin language phenomenon can be summarised as a lexicon that is largely given by the input and a grammar that, at least in some cases, seems to develop largely independently of the input.

\section{Levels of input}

We may now return to our basic question, namely: what level of input is necessary for language to arise? In the few cases where we can be reasonably certain that a normal child has been exposed to no input, language has not developed. Now, when language first originated this must have been the scenario, that is, the Dumbo Factor must have come into play: a creature that had a certain ability but was unaware that it had this ability must have be- 


\section{Bernard Comrie}

come aware that it had the ability. We know of no clear modern instances of this happening, but this is not in itself evidence, since most children have the possibility of acquiring language under normal conditions and do so. At best we can say that we have no direct evidence of the Dumbo Factor coming into play, but circumstances make it unlikely that we would encounter such evidence. In one sense, then, our basic question of how humans came to know that they could communicate by means of language remains unanswered.

If a lexicon is provided, then it seems that, at least in the presence of a community of potential speakers, language will develop, and will develop rapidly. The best documented example here seems to be NSL, whose predecessor, the protolanguage Lenguaje de Signos Nicaragüense, provided at least a rudimentary lexicon from which a fully fledged language could then develop. If Bickerton's bioprogramme hypothesis is correct, then the development of creoles would be another example, although as indicated in section 3.2 the evidence is less clear here. Twin languages may be a further example. Thus, perhaps somewhat surprisingly, the main task in creating language seems to be providing the lexicon. Now, since protolanguage clearly has a lexicon, the early humans who had developed the ability to acquire human language but did not yet have a human language to acquire could in principle have simply taken off from whatever protolanguage they already knew and expanded it. If this scenario is correct, then while the provision of a lexicon is a task that does not in itself require the linguistic ability of humans, it is nonetheless a crucial catalyst for the realisation of that ability.

Can a language arise simply by stimulus diffusion? This term, borrowed from anthropology, means that the mere recognition that some other individual or group has a particular ability would lead the observer to realise that ability. To return to our initial analogy, if Dumbo had observed other flying elephants, then he might have realised that he had this ability and have started to fly. The question is difficult to answer, given that the crucial step of provision of at least a basic lexicon seems to be a step in the development of language that does not in itself depend on fully fledged linguistic ability. Even NSL, which has been studied from so close to its origin, has a forerunner in the protolanguage Lenguaje de Signos Nicaragüense, which provided the initial lexicon. Thus the question remains open whether a group of humans lacking language and a lexicon but observing another group of humans that have language would solely on this basis enter straight into language without going through the initial stage of developing at least a rudimentary lexicon. It may even be that the question is moot, with lexicon creation taking place anyway under stimulus diffusion. 


\section{Analogies: writing and ape language}

It may be useful to consider an analogy to the conditions under which human language can arise by looking at the origin of writing systems. Of course, there are striking differences between the two. Under normal circumstances, language develops inevitably in the normal child, while writing is a recent invention in human history, is absent from a large number of speech communities, and is normally learned through explicit (and at times painful) teaching. There is thus no sense in which we would expect a human individual or community to come up with writing.

The number of independent developments of writing systems is small. In all likelihood the development of writing in Meso-America that led to the Mayan hieroglyphic writing system was completely independent of developments in the Old World. And it is possible and in some cases probable that some Old World writing systems - Chinese, for instance - may represent ex nihilo developments (Boltz 1996: 189-190). Most writing systems can be traced back to at most a small number of ancestors, in the way that the English writing system can be traced back through Latin to Greek and beyond. However, such direct ancestry is not the only possibility.

Writing systems can also arise by stimulus diffusion: "some visionary, aware simply of the existence of writing among nearby peoples..., sets out to devise his own system" (Daniels 1996: 579). Perhaps the clearest documented example is the Cherokee syllabary (Scancarelli 1996: 587). The inventor of the script, Sequoyah, was a monolingual Cherokee speaker. $\mathrm{He}$ observed that English speakers could use marks on paper to represent their language, and set about devising a writing system for his own language. While the actual symbols are largely based on Latin letters, their values in the Cherokee syllabary bear no relation to their values in English: a symbol like an uppercase $\mathrm{W}$ represents $l a$, whereas one like an uppercase $\mathrm{Z}$ represents no. But even more strikingly, the linguistic basis of the two systems differs. The English system is, however imperfectly, an alphabetic system, with ideally one symbol per phoneme, while the Cherokee system is a syllabic system, with ideally one symbol per syllable. There is, for example, no consistent representation of the phoneme /o/: the symbol described for no bears no resemblance to the symbol for go (which looks like an uppercase A) or that for do (which looks like an uppercase V). 


\section{Bernard Comrie}

Thus, despite the considerable ontogenetic differences between language and writing systems, in the case of the latter we have extremely few instances of creation ex nihilo, rather more instances of stimulus diffusion, and a vast number of cases of direct ancestry.

A different possible point of comparison would be the language-like communication systems that have, with some degree of success, been taught to nonhuman primates. What is particularly interesting here is that no nonhuman primate seems spontaneously to have come up with a substantial lexicon, although nonhuman primates clearly have the ability to acquire a reasonably substantial lexicon as a result of direct instruction and, in the case of Kanzi and other bonobos (formerly called pygmy chimpanzees), by imitation of others that had been taught this lexicon (Savage-Rumbaugh et al. 1986). Once again, provision of a lexicon appears as a prerequisite for linguistic development, here of the protolanguage (in Bickerton's sense) attainable by some nonhuman primates.

\section{Conclusions}

On the basis of the empirical material ${ }^{5}$ and hypotheses relating to them as discussed in the preceding sections, it seems that we can go some way toward answering the question of the necessary input for successful language creation. Under normal conditions of language acquisition, essentially nothing new is created in the long run, and this is what has characterised the linguistic development of most humans throughout human history. At the opposite extreme, if no input is provided at the crucial age, it seems that language is not created anew, a conclusion that has interesting implications for the origin of human language in the first place. If a lexicon is provided, it seems that children can create a grammar anew, though apparently only in the presence of a sufficiently large community and only with continuous input from new cohorts who enhance the language-like nature of the communication system; the most striking evidence comes from deaf sign languages, while other possible sources of evidence might be creoles and twin languages, although especially in the case of creoles there are strongly competing hypotheses. Creation of a lexicon seems somewhat surprisingly to be something of a stumbling block: children who are not exposed to language at the relevant early age do not spontaneously create a lexicon. Creation of a lexicon is, however, possible, since deaf sign languages have lexicons that are in some cases of demonstrably recent origin. They may, however, have been created by stimulus diffusion. 


\section{Notes}

1. This article originally appeared in Linguistics 38 (2000): 989-1004. I am grateful to the editor and publisher of Linguistics for allowing this reprint.

2. One might exclude certain monastic orders with a vow of silence. But these are hardly normal communities, for instance in terms of the possibility of internal procreation.

3. Compare the way in which the transparent pictures of the earliest Chinese writing soon give way to conventionalised, noniconic transformations. Iconicity between form and meaning in the lexicon seems just not to be a strong desideratum of human language.

4. The language here referred to as Nicaraguan Sign Language is called Idioma de Signos Nicaragüense in Spanish. English unfortunately has no obvious way of distinguishing between Spanish idioma and lenguaje.

5. It may be worth noting that even as philosophical and apparently aprioristic a treatise as Herder (1772) was recognised by the author as being subject to revision in light of new empirical discoveries. In the first edition, Herder claims that apes are unable to speak human languages despite having the same anatomy of the vocal tract. In a revised edition, he notes that anatomical investigations carried out in Holland showed that his presupposition was incorrect: apes have a different anatomy of the vocal tract. 